\title{
Authentic Needs and Genuine Productivity
}

\author{
Alexandru Jivan ${ }^{1}$
}

Miruna-Lucia Năchescu²

\begin{abstract}
Human kind doesn't need revising the treaties but its own judgments!
Nicolae Titulescu
\end{abstract}

\begin{abstract}
The paper deals with a critical debate regarding the common conception on human needs and on their fulfilment through the concern for productivity and growth.

It starts from the most common way of perceiving (and, implicitly, of developing) the economy, which is reappraised on the grounds of genuine liberalism; several routine approaches in economics and most common concerns in the economy are put under question.

The debate brings conclusions related to a widened area of issues concerning the assessment of economic activities and core educational recommendations, implying interventionism focused on developing responsibility on the very long term.
\end{abstract}

Keywords: $\quad$ human needs, productivity, genuine liberalism

JEL classification: D24, D31, D63

\footnotetext{
${ }^{1}$ PhD. Professor, West University of Timișoara, Faculty of Economics and Business Administration, e-mail: alexandru.jivan@e-uvt.ro

${ }^{2}$ PhD. Associated Professor, West University of Timișoara, Faculty of Economics and Business Administration, e-mail: miruna.nachescu@e-uvt.ro
} 


\section{Introduction}

Economic growth is, actually, one of the most invoked issues in the world, in the past decades, productivity and competiveness being assumed as the routine ways to achieve it; but the permanent concern for such goals finds itself, in the very long run, also into perverse results: we are living the most deep and long crisis's effects we have ever knew.

Our paper does not analyze monetary and fiscal policies or macroeconomic management in a certain juncture, but just puts under question the most common economic thought that is assessing the economy by the criterion of productivity meant to cover a certain set of needs. Both this set of needs and the common productivity growth methods are under the pressure of the market economy, market that determines these needs and methods and develops them according to itself.

If economics succeed avoiding routine, interesting ideas can be revealed.

In this paper, we have discussed the most common approach, regarding the fulfilment of needs, wherein the common concern for productivity and, in a focused way, for growth itself. The paper puts such an approach under question, on the ground of - and by using -certain genuine liberalist principles of productivity and the principle of servicity, which can be considered a very different approach than the common one. Suchan original approach has allowed the distinction we make - and underline - between common productivity and growth view, on one hand, and the profound value of the economic actions (in the spirit of servicity), on the other hand.

In respect to the literature, we are just looking for the main elements that the present paper contradicts and for the most supporting thoughts in the field, namely we present (i) a reaction to the common approach towards productivity, i.e. as a ratio between the calculated "production" (for an economic entity) and the associated effort of the entity (factors consumption of the entity). Taking into account the quasi general approach that is based on the productivity (as it is commonly known and calculated), this approach and its developments in the orthodox economics do not make the object of the present study, as such an approach brings nothing new as knowledge or for the conceptual development of our thesis. This common approach is only taken into account as a general reference, in order for us to be able to bring corrections according to $(a)$ the lessons given by the deterioration of the natural environment and $(b)$ the still existing long economic crises that we consider to be the natural course of the dominant productivity and economic growth ideology.

Moreover, our approach (ii) is clearly different (also from the methodological point of view)from the business approach that is also present in our days theoretical economic thought (economics), especially in the neoliberal developments that look at the economic reality through the company's eye and put the company and its actions in the core of the economic thought.

Such comparisons against the dominant economic ideas are defining elements of the servicity theory. Therefore, (iii) the present paper can be included in a line of 
developments (too little known) from the field of servicity ${ }^{3}$ and makes reference to different papers of the authors (in the same field) as well as to certain milestones from the genuine liberalism and from economists which are rather heterodox than included in the mainstream economics.

The paper is a theoretical one, that doesn't have as objective to prove the ideas through data analysis, and has not the aim of applying them at this stage on particular cases.

We conclude that the problem of perverse economic effects may be put in connection with the development and generalization of the modern principles of the consumption society, in what concerns the needs and productivity. Therefore, that is why servicity, rather than productivity (as it is commonly approached and calculated), should be applied in economics. As a consequence of our study, we are offering educational suggestions in order to make people more responsible towards their actions that stand at the basis of possible future crises.

\section{The start of the error}

The genuine liberalism comes from the French Physiocracy (in this concern, please see Jivan, 2014, section 1, where references to Quesnay, 1766 were made); but also the profound scientific conception of Adam Smith could be quoted when he talks about "the consideration of the general interest of society" (Smith, 1759, p. 152), which is called to the assistance of justice.

In fact, on page 125, Smith (1759)4 speaks about "the propriety and fitness of recompensing them [the merit and good desert of actions], and making the person who performed them rejoice in his turn". On page 147 he says that "though no man in it [in the society; n.n. our note] should owe any obligation, or be bound in gratitude to any other, it [society] may still be upheld by a mercenary exchange of good offices according to an agreed valuation." (see also, infra, section 3 ).

Such liberalism suffered a historical reset: if some compare today's liberalism with the Physiocrats', the original genuine liberalist spirit is now forgotten and we can see how far we are today (in the economics approach) from the efforts of Quesnay or of Smith to distinguish value production or productivity (see our approaches, debates and developments on the topic, in Jivan 2007, 2008 and others; the most recent are our papers2013c and2014).Today, the genuine liberalism approaches are no longer valid. We have a new culture. For example, a certain cult for economy - as a speculative or negotiated private profit development- can be perceived. The consideration of the general interest of society is rather ignored, as we can see from the ecological and environment destructions.

\footnotetext{
${ }^{3}$ Such approaches were also present in papers such as Jivan, 2013b, 2013c, 2014.

${ }^{4}$ His economic conception (Smith, 1993), can be better understood if firstly his more general approach is perceived (Smith, 1759).
} 
Veblen points out the difference between (i) exploit (conceived in the individual interests of the actor, by a conversion of a pre-existing value) and (ii) true effort aiming at actual creation, in the purpose of bringing values (usefulness) to humans, by a fair contribution. The effort of creating values (i.e. of producing or generating the means of life) is called labour, industry or drudgery by Veblen, in his historical debate (concerning different evolutions, coming from the roots of the beginnings of humanity). "Industry is the effort to create new things, with a new purpose given by the fashioning of its maker out of passive ('brute') material5: while exploit, so far as it results in an outcome useful to the agent, is the conversion to his own ends of energies previously directed to some other end by another agent." (Veblen, 1953, p. 27-28) We emphasize on such an excellent distinction between the two different concepts.

"Such employments as warfare, politics, public worship and public merrymaking, are felt, in the popular apprehension, to differ intrinsically from the labor that has to do with elaborating the material means of life."(idem, p. 25-26). There is clearly a resemblance between Veblen's view concerning the definition of 'exploit' and the delimitation, done by the Physiocrats, of the society's 'sterile' activities. In both cases we have the opposition against the genuine productivity (i.e. to the creative activities that bring a net, general and indubitable plus of utility, ensuring the fulfilment of humans' society needs, in consistency with the general interest of society).

I would add here too that, nowadays, most of the immaterial means of life should also be taken into account, and their creation or performing should be considered creative (especially the intellect-intensive ones). In the era of services and in a knowledge-based economy, the contribution of scientific research, teaching, medical performance and such ones is evidently the most creative and the most productive in the interest of humanity and progress (Jivan, 1995).Therefore, they should be included in an extended (postmodern) concept of labor (even if they do not require a common physical effort, but knowledge, intellectual capital). That is firstly due to their productive contribution, in general purposes, concerning not only the actors performing such activities, but most of the environment, the entire benefit of humanity. Of course, the individualist purposes of many intellect-intensive actions and activities cannot be ignored, some immaterial activities meaning exploit in an obvious manner. But, at least the public teaching meant to educate the young generation in the spirit of humane principles - and other such examples (representing intellect-intensive activities proved as being most contributing to the development of mankind) are arguments for their inclusion in an extended actually productive concept, by updating the materialist former approaches.

In the economic environment, we can often find (as common, normal and perfectly legal according to the most spread laws) that, under certain favourable circumstances, negotiating from a force position and in general, in a very skilled manner, a company can obtain from its negotiating partners, very profitable contracts. The advantages can be

\footnotetext{
${ }^{5}$ Here the meanings of creation must be extended, of course, to widened dimensions, consistent with nowadays levels of human actions, needs and superior purposes. But the quoted fragment is relevant for the meaning that results from the next (following) sentences.
} 
obtained when buying goods or services or when selling its products. Therefore, it is quite common for the company to get cost savings or extra revenues (exceptional ones). Or, on the other hand, it is quite common that due to some changes in the forces reports, or due to political instability, the currency of a certain country could be affected in report to the other currencies, having a major impact on the whole population of that country. Still, from a scientific perspective, this doesn't imply that, in the first example, the company concerned has become a better "value"-creator (that it is a better "producer", but just that it is a better "appropriator"); or, in the second example, that the nation concerned is now (out of the bloom) "less productive": it only means that it suffers from the impact of the market games. Such games are usually independent from the creative (utility producing) qualities of the actor (company or national economy) itself and cannot be controlled in any way by an individual actor.

In the present paper, our focus is not on the history of this distinction seen by Veblen or by the genuine liberalism of Physiocrats or Classics, but on the existence of such a distinction. Our concern is mainly the present society, in which the (generalised) pecuniary culture has reached, in our opinion, a maximum peak of intensity. In our view, the present state of the "pecuniary culture" affects the understanding and application of liberal principles (that are very changed from the original ones).

In our paper, we take into account the enlarged (and adapted to the present society) meanings of such behaviours, actions and terms that Veblen analyses from a historical point of view. Still, in our approach, combining the Veblen vision with the class distinction according to productivity made by Quesnay (1766), one can notice the differences between the creative, productive activities (of "labor" type in the case of Veblen or "productive" activities in the case of the Physiocrats) and those of the "exploit" type ("sterile" for the Physiocrats) of the economic actors that themselves live on the basis of the production obtained by the first ones, through the redistribution of values in the society. The pallet between these two extremes includes a whole series of nuances in which genuine productivity can be put under question in various/diverse degrees.

The reset of liberalism that we speak about in this section is, in fact, a switch from the original approach of liberalism, to some foundation of individualism, yet captive to the group interest of the appropriators, switch that was made due to the interests of the exploit: Still, this is done in perfect consistence with the historical arguments brought by Veblen. The work under the natural forces government got the form of the "invisible hand". Such transformations were unspoken and underground. Therefore, the "unseen" mechanisms are now acting and perceived rather in the way Mandeville described them (i.e. vices, fraud here explicitly included, are supposed to bring benefits6), than in the genuine initial liberal approach.

\footnotetext{
${ }^{6}$ As Mandeville states in his famous/Fable of the Bees (in his view some can speak about the favourable influence "private immorality" had over "public welfare"; see also Heilbroner, 1994, p. 191). Avner Offer (2012) sais explicitly and synthetically that "Adam Smith rejected Mandeville's invisible-hand doctrine of 'private vices, public benefits' [...].Modern versions of the invisible hand in rational choice theory and neo-liberalism are shown to be radical departures from the ethical legacy of Enlightenment and utilitarian economics, and are inconsistent with Adam Smith's own position".
} 
Such outline meant switching from value creation - as integrated in the natural laws (individuals being parts in the natural human society and, moreover, in the Mother Nature's system of laws) - to stimulating the worst and most basic animal sides of our beings, in generating artificial and destructive needs and, even in evading the natural laws. Such evading is destructive for the principle 'Laissez faire ... Le monde va de lui meme': the grounds of natural functioning of the economic system were undermined. In other words, such invisible mechanisms (rather in the Mandeville's way, than in Smiths', i.e. not only accepting, but even inciting fraud and, generally, vices, as a productive base or a generator of benefits, as a condition for success at individual and societal levels) brought us, unfortunately, too many very visible perverse effects... And here we are in the present long crisis.

Amartya Sen (2000, p. 18) brings the example of Japan, that obtained success under the circumstances of "the rarity of littering, the infrequency of litigation, (...) and a lower rate of crime"; such way means, in our approach, rather working together, having a moral approach, than free unlimited fight on the market. We tend to conclude that such practical reality of success rather contradicts than checks the assumptions of the way of understanding the market mechanisms consistent with the modern destructive consumption economy.

Therefore, we consider that economics should take into account (for a scientific approach) some important approach enlargements:

- The temporal enlargement: besides the usual approach (that is usually limited to short and medium term), one should analyse the long and very long term results (Jivan, 2011a);

- The space enlargement and the avoidance of the enterprise focus: the analyses based on individualistic approaches are adequate for the enterprise level (in management approaches usually having also a marketing view) but are not adequate for the scientific economic theory that should overpass such levels and get over the myopia of the market and try to identify the implications of the complex effects of any economic action (e.g., the "externalities" theory stipulates that these are "external effects" from the enterpriser's point of view; but the economics analysis should be a general (complex) economic point of view. The economics research should take into account the enterpriser, as well as its clients and environment and the way it cooperates with them too. It is relevant in this respect the "co-production with the consumer" theory from the services economy and its development towards the coproduction with the environment systemic assembly found in the servicity theory, according to Jivan, 2013c and Jivan, 2014. The environment "co-produces", generating a technical progress, factors and conditions consistent with the level of human civilisation of a certain stage of development and of a determining national context, context of a local culture, with certain dimensions that generate a particular attitude towards nature, people etc.

Here we saw the economic actor being at the same time performer (usually called "producer") and client (commonly called "consumer"). See also some developments of the idea concerning the relations of the analysed entity with its environment in the end 
of the section no. 3, from more particular points of view, in the narrow and extended approach of servicity.

\section{Needs generated by our economic-dominated system}

People's needs generate economic action, targeting their fulfilment. Needs are also one of the factors determining productivity, besides other factors. The propensity to (quantitative) growth that defines the modern economy generated itself an adequate system of needs, consistent with such propensity.

The common principles set with regard to the human needs address preponderantly primary perceptions (i.e. sensorial) of the world, in correlation with the human beings' most simplistic drives, which, rather than being controlled by a lofty mind, are only rationalized with, by minds subjected to such perceptions and drives. The almost only criterion economists commonly judge by, consists in mercantile efficiency (i.e. the best performance, on minimum effort). The generalization of the market principles on the map and in the societal field is a reality of our days, economic principles expanding over common knowledge in a factual economic (hedonistic) religion.

This approach is already generalized: among other conceptions (that do not make the object of the present paper), globalization can also be regarded as an expansion of a lifestyle which generated the high pollution and consumption. Therefore, such phenomenon should be looked into, in a discriminative way. When global economic evolutions are wrong, economic science is in trouble. Too many global evolutions are not well enough anticipated.

The literature concerning the "needs" topic (including the well-known researches of Maslow, 1968) is abundant and we do not aim to review it.

Concerning the basic physiological needs, we want to point out that these needs should be revised nowadays. For instance, the need for vital biological resources is now threatened, despite the fact that such resources are capital for health and even for the survival; we refer to resources such as water, air and, generally, the natural - and not destructed - environment. We should be concerned with the environment's purity, temperature, diversity and general quality to support life in best conditions possible. Unfortunately, in our days, water and air, so far natural resources, tend to grow scarce, therefore becoming economic goods. Much of the natural water basins heritage is destroyed by industrialization, while the same industrialization supplies bottled water. The same trend can be identified in what concerns air: we will soon buy bottled breathable air, supplied by the vigilant enterprisers. Paradoxically, such evolutions came exactly because of the economic developments that are invoked as demanded by people's needs. That is because, in the market mechanisms, the need for gain and therefore the productivity purpose always comes first. The natural environment becomes less and less natural. The growth rush - even if declared in the name of better accomplishing human needs - destroys fundamental resources of the planet (like water 
and air) up to a point where even vital needs are menaced. Physiological and psychological impact of such (destructive) developments can be revealed.

But many of the researchers who study the human needs do not even realize such menaces exist (many studies on human needs speak mainly about material needs, as air and water - and, as the entire natural environment, they are considered to be given and not perishable; the fundamental concern that economics has for growth -in the productivity approach -is focused on the purpose of accomplishing material, i.e. pecuniary needs). In this case, what chances does mankind stand to make the economic enterprisers aware of the risks at such a level as to make them cut pollution and take on responsibility? Such businessmen are driven by self-centred profit only, no matter how begot, and not in the least by selflessness or caring for fellow-men, and even less by the well meant field researchers' findings.

The wake-up call to responsibility tends to stand so little chances because positivist economists only take snap shots of reality, as it is or as they see it(i.e. bereft of socialhumane content, sheepishly following of the steps of thought, approach and behaviour of business, which is also the money giver for research). Thus only the economists who have broadened their horizons to cover ethics and sociology firstly stand above business in terms of understanding the complexity of interwoven reality threads, able to teach lessons to business, instead of following it and preaching its interests. Economists will judge amiss, feeling they are beyond morals.

We also want to underline that, even if several needs are bringing the most direct mercantile gain, we should not ignore that, inside our needs, the most important place is (still) taken by the human needs - as we also have, by difference to inferior beings. Therefore, stimulating rather the basic and instinctual needs is perverting human beings (see the laws of advertising and of success trade; developments on the issue in Jivan, 2013a).

Pushing the animal side to the fore (in terms of instincts, drives) rather than human aspirations generates a reverse process of humanity rising out of animalism. Or, the latter (human principles), rather than the former (animal features), should matter most: they are true human needs, even though a few of unhappy fellows of ours deny them, or at least ignore them, or, worst, do not even know them when they see them. We deem that any approach of human needs and activities should consider the hierarchy that was conceived by the Hellenistic philosophy, philosophy that were safe from the today's new "religion" (the economic one).

Activities really befitting man as a superior being are philosophy, sciences such as astronomy and mathematics, arts and culture. Economic activities are inferior; but are normal when practiced for getting the individuals a good life (by tilling the land and doing all that farming demands for providing food, by providing for manufacturing the goods and performing the services normal life takes). On the other hand, if they are not meant for getting people their good lives, but for enrichment of the enterprisers (under the "greed need", in Sedlacek's terms (Sedlacek, 2012, chapter 8, who sees economics 
rather as a cultural phenomenon ${ }^{7}$ ) then such inferior activities are not even natural or justifiable anymore: sheer degrading and dehumanizing Chrematistics. The market alone will not show such a hierarchy of needs. Superior criterions are requested and, in a knowledge society, science should be able to reveal such criterions and such hierarchy, rather than put and let them at the back and call of the mercantile incentives (mechanisms of incitement) and market mechanisms government.

We tend to see specifically human activities as not only static but also - especially so dynamic for the human being's growing out of the animal and further human development: such are the drives that made us superior and which give us a chance for perfection as humane. What does not make us rise keeps us low and, worse, may elicit our animal side, even degrade us (body and soul) enslaving us to dope, sexuality and money.

Ignoring such risks is inconsistent with today's knowledge society we build. Approaches form the prospects of the immediate needs are marked by myopia, as is also the strictly economic approach. The need for economic growth stands for the majority of the scientists as the only spoken rule. Paradoxically though, bringing to the fore the basic animal needs still leave in the background sine-qua-non needs like safety, health, air (as already said) and such others. The needs deemed as immediate are thus proven to belong with the animal side of the individual, inconsistent with the broad human horizon view. Even if, on the short term run, wealth is placed first, in the needs hierarchy, placing wealth first also on the long term run has already been proved fallacious; and also on the very long term run. Mankind (and economics' assessments here included) must adjust such optics. The very long run approach should orientate the debate on the defining of the human (and humane) specific needs, and, accordingly, on economic actions consistent with such widened idea. Another kind of productivity would come out, rather than the most common one.

Similarly, the way societal psychological knowledge favours identification of needs such as self-promotion and rising in societal rank (naturally superior to physiological immediate needs), spiritual psychological knowledge should allow for the identification of needs other than specified in the most common models. The elevated nature of the latter caused them to be skipped, as a rule. Culture (i.e. meaning the aria of knowledge that a person holds ${ }^{8}$ ) is what gives us a wide enough horizon for superior scientific knowledge to be possible, going beyond the exclusively empirical stance (of the material evidence), thus coming closer to the deepest hidden reality faces. That is because the culture of individuals (as volume and diversity of knowledge) makes correlations and an open mind to new ideas possible, and generates synergic effects as well as an increased

\footnotetext{
${ }^{7}$ We consider nowadays economy and economics as a product of the recent consumption civilization. In our modern industrialized world, the main concern for profit and enrichment is defining and taken into account as a capital need (and means) for individuals and society.

${ }^{8}$ For instance, culture can be perceived at the individual level, i.e. the level of general knowledge of the individual (if culture is used in its singular form; different levels of culture exist, every individual having his own culture); or it can be perceived at the group level, i.e. the type of traditions, conceptions etc. of a human societal group (if culture is used in its plural form: there actually exist different cultures, different nations or other groups having a different defining culture).
} 
understanding power, namely an increased intelligence. (See also the invocation we already made of the Hellenistic approach on human-specific activities.)

Most of the needs hierarchies lack long and very long term run approaches, seemingly favouring the short term run, so dear to all economists. In fact the very long term run works with communities (family type to humanity): if meant for each individual, approaches will not go beyond human life span. Hence limitative Orthodox approaches at the individual's level prompts ignoring longer term runs, proper to judge the large communities by, nations, mankind, large organizations and centuries old families.

The individual's exclusive viewpoint usually is not accompanied by statements of groups, such as family, organizations, local and national communities. Family only figures as an appendix to the individual's needs, and ranked as less important than others. Such approaches ignore important human needs and the fact that man is a societal being.

In the economic approach, the family is mainly conceived as a need for the individual; but the family itself is not commonly assumed like a central entity in the human existence: that is because the economy (conceived as core criterion of any judgment and analysis and almost as a purpose itself) needs the individuals as labour force holders. The individual can be subordinated to the economic goods, processes and goals, e.g. by the labour market, the "labour mobility" 9 here included. But, on the contrary, the family needs, for instance, stability, which is necessary for raising kids and for the formation of the new and future generations should be perceived to be a first level human need. Why considering mainly the economic needs in the detriment of such family needs? The economy is just a tool for human development and should not disturb family life; therefore, why should not the individual be considered as rather subordinated to such family (and, generally, human development) processes and goals?

Family needs come in clear sight even to those who do not realize the conceptual meanings of such, when reading sociological research on leaving home countries in search of jobs. ${ }^{10}$ The "mobility of the labour economic factor" is an approach ignoring such needs and all the other needs being considered for the only purpose of concurring to support the economic. It means we live for the economic purposes? Such an approach is cynically oversimplifying our lives, by mercantile criterions.

The more advanced a specific society is (i.e. developed in diverse dimensions, such as science, culture and civilization, techniques and economy etc.), the more varied and complex viewpoints will be, up to the top viewpoint, of the planet community or mankind. The needs are not exclusively individual, but rather human, societal, natural,

\footnotetext{
${ }^{9}$ The mobility of "labour" lets many families in trouble, mostly in the poor countries affected by emigration (in Romania it became a real problem).

10 The Romanian parents, having no more jobs in Romania, have to go to work in Spain, England or Germany, for instance, and let their children often home, in material scarcity, in scarce familiar environment, and in scarce education. Such problems - caused by the priority of the needs of the economy (and, generally, of the economic needs) over the human needs - have destructive long and medium term effects for individuals as well as for the society (on a long and very long term basis). Such effects can be reflected in the diminishing of intellectual and ethical levels, in criminality growth etc.
} 
i.e. with respect to our entire environment. The very science of organizations (as a rule seen exclusively from the business viewpoint) is the science of such human communities. Similarly to needs diversifying function of human community's type, needs also diversify function of the time lines viewed(not only short, but also long and very long run; see Jivan, 2011a, and infra Section 4).

\section{Service approach and intellect-intensity}

The concept on which we've based our present analysis - as well as many others in the same direction - is our principle of servicity (Jivan, 2000; see also developments on the issue in Jivan, 2013b and 2014). We've developed the servicity theory as directly affiliated to the genuine liberalist spirit. It is consistent with serving (responding to) genuine human needs, rather than mainly the pecuniary demand generated by the mercantile approach (management, marketing, competitiveness etc.)

Many well-known economic researchers of the Service economy should be pointed out in our days, thanks to the contribution their science can bring to economics - even if still considered as marginal ${ }^{11}$ (see developments of the idea - concerning the contribution of service economics to the general economic science -in Jivan, 2000 and 2013c). One other author that should be mentioned, despite the fact that he does not deal directly with services economy, is Mihail Manoilescu. His view on productivity is that profit does not mean a true quality or value of the enterpriser, but more important the entire earn in the society (and at a planetary level, we add) or of different (other) economic entities (Manoilescu, 2012, pp. 98 and 338, for instance). Such theory of productivity means that not only the enterpriser's profit indicates the value of an economic entity in the economy and the society, but also the income distributed to the largest number possible of side actors, nation-wide, we would even say planet wide and inter-generational. The basic criterion in such an analysis should be the general wellbeing of all (concerning the general interest of society, if we use the words already quoted from Smith), namely a Pareto optimal in a generalized meaning, i.e. taking into account all the possible dimensions to imagine space and temporal dimensions, the personal dimension societal as well as individual; and also complexity that should be better extended to the planet as a whole, nature included).

A more recent most important background for scientific review of the common approach on economic life and mainly on economic science was provided by the important interdisciplinary and complex contribution of Amartya Kumar Sen, who actually clarified important issues concerning poverty, freedom and ethics, providing a new, profound, approach on economics (see, for instance, Sen, 1987/2000 - what we already quoted). But despite all pertinent analyses (made by important economists like

\footnotetext{
${ }^{11}$ Because of the dominance of the industrial approach in economics, rather than the approach based on service theory. Interesting recent developments appropriate to this section can be found, for instance, also in Ramirez \& Nembhard, 2004.
} 
Amartya Sen ${ }^{12}$ ), the 'purely self-interested behaviour' remains an assumption of the most of the "economic religion" propaganda, in practice (for instance in the advertisements) as well as, paradoxically, in the standard economics that is taught to students: this last one provides even "the behavioural foundation of standard economic theory and policy analysis, and the basis of much of what is taught to student of economics" - as A. Sen says (in the book we quoted, p. 17). The whole societal perception of people is built on such wrong assumption on the economy - and such view is not limited to the economy... This is what is preached to us in the modern society, this is what we are educated - by all means and on all the ways - to believe, to involve in our thinking, to do ourselves, to choose as our own behaviour. This generates the consumption society and all the perverse effects resulted (here included the new long crisis).

We underline that the economic activities human beings deploy ${ }^{13}$ consist not only in the efforts meant to bring or to produce the basic goods necessary for life: such activities are more than the technically and technologically extremely developed forms of the activities that usually all beings do for living. It is also not the social organization that makes us, human beings, actually different from the other animal beings; but humans have defining non-animal features. It implies humane needs, as already said (infra, section 2)

The intellect intense activity has a more human, superior and complex character. This is valid even when, by fallacious analogies with labour, conception work is regarded as being "directly productive" (e.g. the case of scientific research being assumed as the producer of theories, ideas, inventions etc.). Still, conception work is not working as a machine (not even a "smart" IT machine), but, having a precise purpose, it puts to work different subsystems, labour and machines being included as functional material elements. Along with these and other sources of energy, movement and transformation, conception work acts upon different material resources.

Conception can speed up the succession of process cycles (e.g. of flow of capital, or increase productivity and efficiency, either as more production per time unit or as better use made of the same resources) or can play other various roles with effects in terms of quantity and quality of such a drive("productive" functioning) and purpose.

Therefore, individuals must be taken into account as human beings rather than labour force owners. If we deny approaching individuals in their 'labour' dimension (i.e. if we refuse to define people by their physical features, and if we focus on our human quality) we can better see that the human intellect does not directly take part in the production process (or economic, in general) It does not produce, stricto sensu, as a production factor, but as an economic agent which fully aware initiates and supervises the respective action. Even when a material action is in order, the role of the spiritual being is purely spiritual (human, intellectual), of conception of such action and of the whole of

\footnotetext{
${ }^{12}$ He quotes a rich literature on the topic (for instance at pages $\left.p .16-18\right)$.

13 See also the interesting developments brought by several important analyses concerning the service economic specificities, like, for instance, Kemppila \& Lonnqvist (2003), Wilson \& Frimpong 2004 and Johnston \& Jones (2004).
} 
the process, under all aspects (e.g. finality, approach, deployment, coordination, followup and control of developments and results thereof).

The resource of the intellectual services is the human intellectual capacity, 'production' being given by the exertion of such faculties (functioning as a process, not a 'stock'), not by consumption stricto sensu of resources (reserves of usual resources being implacably limited, however abundant).

As a rule, economics analyses labour and the material resources extracted from the environment and processed by diverse industries. We believe an at least equally important focus should be placed on the other (intellectual) resources, i.e. information and ideas, even if they are more difficult to analyse, because of the complexity of the aspects involved and the relative simplicity of the data available.

In fact, the knowledge-society focused on such immaterial issues. Even productivity and value can be revealed on superior criteria than the strictly material evidences. Under specific circumstances of availability, utility is and has always been the essence of value (under scarcity with the Neoclassics, and as condition of the value measured by cost with the Classics). Or, availability is begot by activities type services. Therefore the creation is the core of the servicity approach on the economy. And the spiritual and intellectual contribution is defining for creation; also in the economy (Jivan 2013c).Such a view is consistent with the Physiocrat approach (infra, section 1) but contradicts the strictly material value approach and the market results: often productivity - as commonly assessed (measured) - is not genuine, but simply absorbed by the enterprisers that benefit on their environment.

For instance, when a centuries-old forest gets cut down, the economic accounting only records the wood production and the effort such cutting, as the price of the respective economic action. But cutting is rather a destruction (or an "exploit" of a general natural useful environment) than a production (than a true service or a creation of some new material substance or objects bringing an actually bigger service to mankind than the utility of the uncut forest). Wood is central in constructions, for furniture and heating, but also for settling the soil, for producing oxygen, for absorbing carbon dioxide, for grounding the dust, for regulating and offering stability to the climate, on the very long run term. The utility of a forest given by Mother Nature is much more complex and therefore the "service performed" to human society by cutting the forest should have systemic criterions of assessment. Economic life principles must use more complete scientific methods of analysis than the simple ones offered by the market.

Market laws have lead and lead to relocation of a number of polluting companies, from developed countries to the less developed, companies thus following their own interests (such as paying as little as possible as wages and also having to obey ecologic regulations that are less restrictive than those applied in their origin countries). All of this is done simply to cut costs. An economic agent can thrive on his supplementary capacity of absorbing plus-cashing (if compared to partners and competitors), and, respectively of imposing minus-pay (as used to compute the value of his production). In other words, such an enterpriser gets rich as he deprives his competition (by stealing 
their customers away), his clients (by pricing advantageous for him), and suppliers (by paying prices in his own advantage).

Redistributing values between economic agents by a skilled sly management and marketing, must not be automatically taken as truly producing: an absorption (of utility, of values) from the environment, or a redistribution (of assets, property, possessions), does not mean genuine authentic production, unless it is made with the generating of new created value (absolute plus, i.e. generally utile, in a Pareto optimal approach), or with generally valid service performing ${ }^{14}$, in the general interest of society, as Smith said. On the ground of such ideas, we distinguish producing from benefiting. Such distinction we made is not common in economics, because traditional economics almost automatically presumes the profiteer to be the producer (of his cashing in), and therefore records his incomes as his own "production". Moreover, introducing the servicity approach aims at taking into account also what usually is left in the background of the private interest (as well as of many impartial researchers, oftentimes even ignored): a mix of realities we try to reveal by the servicity indicator.

Such an approach means the distinction between(i) consuming from others or from the environment (regardless of the set manner of parting the land as exclusive property of certain persons), and (ii) actually creating value, with the contribution of "God given rain and sunshine", i.e. beyond debate and interpretation, effective plus, as in the Physiocrat approach on production (opposed to "sterility"15).We point out a conceptual difference between (ii) getting a contribution to the values of the system (society, mankind and natural environment), on one hand, and (i) getting only a private surplus that is just redistributed or attributed by the market, by negotiation on the other hand. Attributing by the market is done by the constraint for some, and advantage for others, caused by various differences of circumstances (implicitly implacably generating inequity),or by an advertising that became overwhelming for consciences and for the independent power of decision ${ }^{16}$.

The approach in terms of creation in the benefit of the whole environment comes as a corollary of the economic thought we invoked at the beginning of this paper (and developed in Jivan, 2006). This well correlates to Manoilescu's observation (already mentioned before) and to the extension to the entire environment (extension we made from his approach): such extension includes the whole socio-human and planetary system, nature included. Common productivity expresses only the producer's viewpoint; the servicity means also expressing the other aspects of utility besides profit recorded by the economic entity for itself. Servicity therefore is a wider efficacy indicator, concerning

\footnotetext{
${ }^{14}$ See also Veblen's idea of 'exploit' (infra, section 1).

${ }^{15}$ Sterility attributed to those economic agents that exist (and are represented as so in the Quesnay's economic table) and act on the economic scene, but live out of what is produced (by others - those that are creative). They just "manage it" (they can manage to live and to develop different activities in the economy), they buy and sell and perform other "sterile”, unproductive and simply redistributing activities.

${ }_{16}$ Respectively under pressure of promotions, or not; consequently the consumer may choose, being truly informed or formally averted, i.e. by emotional impulse, artificially generated.
} 
the whole output. It is wider than other indicators that can be invoked (such as performance; see Jivan, 2013b and 2014).

We can say that the servicity indicator begins its conceptual contents with the sense of the term serviceability ${ }^{17}$. As any economic activity is meant to a beneficiary (and not to the own direct consumption of the one performing that activity), any economic actor generates services for the beneficiaries and takes advantage of the effects generated by other performers. Therefore, servicity assesses the output of an economic activity by the service induced to the beneficiary related to the service received (Jivan, 2000, p. 104):

$$
\sigma=\Delta S / S p
$$

where: $\sigma$ is the servicity in its narrow meaning, $\Delta S$ - surplus of services or the utility felt by the beneficiaries (the performance, the "well done" to the customers and received by them), $S p$ - the effort made by the concerned (analysed) economic performing entity, respectively its spending, its contribution of production factors involved.

If at the numerator we add the gain of the enterpriser - the "well done" for himself (i.e. if we here include also the productivity for the enterprise), we have the extended meaning of servicity. See also the observations we noticed in the end of the section nr. 1, where we introduced the proposal of seeing the enterpriser in an innovative way: by combining "producer" and "consumer" theories.

The enterpriser tends to fend for himself: economics should not care do it for him (management, marketing and such like being well developed sciences suitable enough to do it). Economics should therefore preponderantly care for angles of analysis commonly less considered so far, for other approaches than the routine view of the enterpriser, specifically with the purpose of discovering which aspects are ignored by the enterpriser, by the business approach for various reasons and with the purpose of studying such aspects, too. Different from focusing only on the interests of the concerned economic entity, such approach is fundamentally different from the common approach in traditional economics.

People may profit in different ways, but certain non-ethical enough actions can be not accepted by their consciences; therefore, several prefer not to gain on the market (i.e. several may have a human responsible attitude, and not the "rational behaviour", behaviour which presumes that any actor wants only to profit on the account of his environment), even if they will no more get the best place in the market competition or will no more be most 'competitive'. Amartya Sen (2000, p. 11) underlines that "Even if the characterization of rational behaviour in standard economics were accepted as just right, it might not necessarily make sense to assume that people would actually behave in the rational way characterized." He makes a profound analysis of behaviour, as internal consistency of choice and respectively, of maximization of self-interest. "The self-interest view of rationality involves inter alia a firm rejection of the 'ethics-related' view of motivation. [...] To see any departure from self-interest maximization as evidence of irrationality must imply a rejection of the role of ethics in actual decision

17 Of the synonyms of the word serviceable (cf. Geddes \& Grosset, 2006, p. 669), we choose: beneficial, helpful, profitable, and useful. 
taking [...]" (Sen, idem, p. 15). "Universal selfishness as actually may well be false, but universal selfishness as a requirement of rationality is patently absurd." (Sen, idem, p. 16). It would be relevant to add that the meanings of value, others than the economic, e.g. from music and painting, even if briefly, by comparison to the large space the economic meanings take in the dictionary (see for instance the space occupied in the explanation in a dictionary source we are quoting ${ }^{18}$ ) - and, probably, as well even in our high level human collective mind -, have also qualitative and moral valences, like the philosophical meaning, while the meanings in mathematics and physics tend to stay neutral.

\section{Effects concerning economic growth}

Human beings should come to a change in their approaches of economics and the economy itself. The only suitable growth in nowadays conditions is the relational economic growth, where organizational returns are specific to growth, similarly to scale (quantitative) returns that are specific to traditional (quantitative) economic growth. This economic growth is a qualitative one (Jivan, 1995, p. 97).

Services-proper are relational par excellence, but in the market economy all human activities are relational. In the vision of the growth of relational economy, conceived as the assembly of services performed in the benefit of customers, all of the economic activities will be apt to be judged by their servicity (see infra, Section 3).

A high relationality means better accomplishing of functions all specialized and high servicity, the synergetic outcome thereof surpassing the total sum of the inputs, i.e. higher utility will occur). The complex product is of higher utility than its component parts.

Being called plus-product (for Physiocrats), plus-value (for Marx), profit (in the usual approach), or surplus (in Maurice Allais's theory of surplus- Allais, 1978), the value created is relative, in respect to the economic agent concerned. For instance, the proper creator's (producer's) and the holder's, profiteer's or user's perceptions, are not the same. Such differences generate diverse attitudes on the market and different respect for the value and, implicitly, for the space and temporal environment. Therefore, the scientific approach in economics must be as widened as possible, and should not privilege any of these approaches (the common approach is rather or even exclusively the one taking the side of the enterprise).

As long as Mother Nature took care to rebalance things gone astray, people could act in support by focusing on goals like campaigning. On short term run, campaigning yielded the targeted results, in terms of productivity growth. As all such processes ran naturally and Mother Nature filled her part as people expected her to, in spite of human aggression (i.e. making for balance, people thought things would go on the same way

${ }^{18}$ Stănciulescu A. (2005), p. 1446. 
forever). Well, Nature is so out of balance that it cannot put itself back on the track, unless the aggressors intervene in order to make up for the destruction they made.

Industrialization has been, from the very beginning, a speedy cover up campaign of needs, becoming in time, more than a campaign, for meeting at times absurd wishes, motivated by profit, under the circumstances of an unethical liberalism. Switching from the short and medium term runs to the long and very long term runs can no longer allow for such misbalancing focus (Jivan, 2011a).We need to preserve an environment, wherein our most necessary and beneficial actions may be sustainable as well.

Avoiding the natural perishables (i.e. a natural law, with a radical role in the price natural mechanism; see our developments in Jivan, 2011b) alters the price system that becomes unnatural, all of such system's fine mechanism needing self-balancing, and all equilibriums being affected. Market proves itself functioning even perversely: its mechanisms are no longer trustable with information, even if apparently assumed and credible, infallible as some might believe. Hence all prices are fake, just as most of the products have become (they are produced with synthetic aromas, preservers and such like). Thus goods seem to smell naturally, are coloured as per nature, but do not come from natural sources; they are copied. Moreover, goods should decay as per natural perishables, but chemicals therein have killed the life within, making guaranty periods impermissibly long.

One cannot say that we can live without growth. But greed (we remind Sedlacek's term), being an animal drive, is a natural instinctual need gone artificial because it was pushed too far, to a denaturising extreme, by a profit (and profiteer) logic. The whole of today's economic theory, especially applied economics is based on the concepts of economic growth and productivity growth. Economic indicators also include changed forms of obsessive productivity: efficiency, competitiveness (as a relational component, varying with the other economic entities, trans-nationality factor included, as if resulting from all of the above). Growth (of productivity and of the economy in general) is thought of as permanently desired, as a basic prerequisite, able to all by itself produce the solutions to all problems, an entity whose absence would make the economic and society progress impossible.

Economic growth actually equates the ever faster pace at which we buy new shirts, cars, furniture, carpets, floor tiles in the bathroom (extended along the corridor, too) and such like. Economic growth also means throwing away all old things, never mending anything (under today's abnormal economy ${ }^{19}$, buying new stuff becomes cheaper than mending, in terms of the routine individualist analysis, focused on the enterpriser and in terms of the set market prices). All (truly beneficial) evolutions should be judged in terms of the general interest on the very long term run, and of the general effort deployed: costs to nature and environment must not be overlooked among the effort types concerned, in all analyse aiming to be scientific and impartial (unbiased).

19 Jivan 2008 and $2011 b$. 
Moreover, industry (through productivity) makes them cheaper than a few decades ago. Still, in reality, the need for them (and therefore their utility) is much lower, as those goods already existed. Their replacement is just a caprice, a fashion etc, and not a real need. The plus of utility brought by their replacement is insignificant even in respect to the small prices offered by the high productivity. This means that the population actually pays for the enrichment of the producers, for artificial needs or, in other words, for small or insignificant surpluses of productivity, while those energies could be used for the many other unfulfilled needs of people (especially of other people ${ }^{20}$ ).

In the modern economy - based on the logic of quantitative growth (mainly based on growing consumption) -durability has almost vanished as a quality factor(e.g. often in footwear, ready-to-wear industry and such like goods, even the long-life service goods) as fashion changes, goods are made for short term usage, thus increasing consumption: all for more and more money, for bigger GDP, for grown calculated productivity and for other such like recorded growth of quantitative economic indicators (see also infra, the next section).

\section{Conclusive remarks}

During the glorious times governed by industrialization dreams, many technical novelties, thought of as breakthroughs (e.g. famous DDT), in time proved seriously detrimental. The gap between the extreme enthusiasm and the extreme disappointment means much more than just the difference of knowledge available at various points in time. Simply put, you could say that plus knowledge enables more thorough knowledge, thus excusing early times for not being able to foresee the negative side of things which later times revealed.

Considering the short term needs, e.g. economic first, and not the long, or very long, term needs, can often prove perverse effects. In fact, the economy in the European Union also considers, by priority, dimensions of life others than strictly the economic, such as social and environmental. As for the visions of different cultures ${ }^{21}$ (e.g. in China, India, Japan, Africa...) their very antiquity speaks for them, if such peoples did not give in yet to individualism ideology pressures, in spite of the evident overwhelming progress manifested by today's globalization ${ }^{22}$. Present debate (in view of servicity) is made with respect to the actual service brought to the whole societal and economic environment, Nature included.

In such an approach, the interest for productivity and its increase, in general for economic growth, was also put under question in this paper. We criticize that the same principle, of the short term run results, was applied to education, mainly in the last

20 If we still can have the general interest in our minds.

${ }^{21}$ Contrary to the meaning used in section 2 (culture with a singular form) we take into account here the meaning used in section 1, namely culture in the extended sense of the term (cultures in the plural form).

22 We noticed (section 2) that, among other meanings, globalisation can be regarded as an influencing or replacement of the local cultures by the commercial, economic, business culture (that of market and consumption). 
decades $^{23}$; and, moreover, under the pretext of respecting the requirements of a knowledge society. ${ }^{24}$ Other recommendations than the ones already presented during the debate, can be advanced even for the education system (also concerning the propensity to many reforms, like those implemented lately into the Romanian tuition system): unfortunately, a big number of such reforms are not governed by a long run vision and just follow the short run interests.

The present paper underlines that the human character of the needs taken into account is (or should be) regarded as a priority for all human beings, rather than the economic side of needs, which looks like being assumed as prior to all, in most approaches and analyses, both applied and scientific ones.

If we consider all perverse effects of the approach of productivity and growth (the recent or still present very long crisis included), we can conclude that the most common tools (used by individuals and by governments in the practical economic life, in everyone's business), as well as the very assumptions (made in the economic science) and the routinely invoked (economic) goals are, in most cases, wrong or at least they can be put under question. Their starting and main fallacy is that the invisible hand was let to function in the manner described by Mandeville, i.e. accepting to do 'bad', assuming that it will bring welfare; and it was not directly orientated to the 'good'. The meaning of good and bad should not be regarded only from the perspective of the common sense. In the perspective of the economic science, consistent with the knowledge society, they shouldn't be taking sides or be limited to the "myopic" perceptions (local, short term, individualistic) but be considered in the enlarged manner of the generalized Pareto optimal. The common economic approaches (and almost all common indicators) assess diverse aspects that are not generally 'good' (i.e. they are not 'good' in all circumstances, in a Pareto optimal approach at the largest possible systemic scale). But often they describe immediate local and individual 'good' that is not verified anymore at a larger systemic scale, and the job of making the 'good' at the systemic scale is left to the mercy of the invisible hand, hoping that it will transform the very particular (and often obviously destructive) profit-making, in a generally valid and adequate 'good' for humanity and for our planet-home. We are living in a world of cunning and of perverse effects to the actions that pretend to bring better conditions to individuals.

Thus, humanity lost its moral reference points, using another religion: the economic (mercantile) one. Individuals (even if accepting or not such ideology) are annoyed by all means, until they become obedient to the gods of the market, to the mercantile gods' interests.

The stake of formal (calculated) productivity is not to increase the sum of values and utilities, but to get as much as you can from the others, through means of management or marketing or other business campaigns or techniques Competitiveness and the important business goal is to find ways of getting yourself richer, most often (and the

${ }_{23}$ (Mostly in Romania; but in other countries too; developing this issue was not the purpose of our present paper, but such issue could be well involved in the topic).

24 Jivan et al (2010). 
easier) on the expense of the others and of the environment, rather than by creating something that would enrich the world assets.

The automatisms of the market have a very big potential. They can be very useful, but also very destructive. The individual action is not the universal panaceas; but it must be well oriented, into a regime of global responsibility of any economic entity. The servicity approach suggests putting under question the economic conception developed (in business and also in the economic theory) on the basis of Mandeville's famous fable. Such economic conception has an impact potential not only over the business practice, and the dominating economics itself is that conceived according to the business logic (which is appropriated for the business interest zone, but it is not appropriated for the scientific interest zone, as this one is a more general knowledge valid one, or in other words, it is one of the general interest of mankind).The servicity concept proposes an economic (and social) system, where artfulness and perversity would not be developed, but limited; would not be incited, but disheartened. It could be a system where the concern would be rather for intellect, spirit and humanity, than for profit and material life. Such a system could be developed mainly by a long run term education consistent with servicity approach.

The lower the productivity of a country, the bigger its responsibility (of the authorities) regarding the promoting of the intellect-intensity, in consistency with UE principles of knowledge economy and inclusion. Highly specific economic policies are therefore needed, for directing investment into immaterial activities, like mainly education and research, here included investment into creation of better working conditions thereof. In several poor countries, the intellectual resource exists, and must not be wasted by selling it as a simple labour factor or migration to the developed countries, but needs to be saved and turned to the best account, as the most valuable capital such countries own, in the benefit of their human communities (families, societies, poor countries), communities which supported the effort for investment in human capital.

Besides the references to immaterial investments, conclusions also result concerning consumption society. (In Jivan, 1995, p. 95, we also built a new economic growth model on such principles, in a synergetic conception: the approach of such model is different by comparison to the traditionalist economic thought).

The science (including economics) - and all humans - should judge if the needs that suppliers say are being ours, are actually ours (of humans, generally speaking), or they are induced (most of them)by the market system of mercantile productivity. Learning, teaching, informing (from diverse sources) and most deep analyzing should led us to the true needs and true activities that better accomplish them. The truth can seldom be at extremes: usually it is in the middle of things, even if deeply.

The debates in our paper work as recommendations, for individual and societal entities which are deciding our lives. The most important - in respect for the servicity approach - is to answer (in any action case): how good is this going to be? And the reference of such 'good' is the most liberal and the most general possible (in a Pareto optimal approach), in diverse dimensions (including space, temporal and highly humane). 
In summary, the paper described a new approach, by which different sights and aspects of the economic reality can be revealed. Such debate is relevant due to the enlargement of the horizons presented. Further studies will be necessary to better exemplify and detail, by analyzing significant practical cases - practical cases that were not included in the area of interest of the present research. Therefore, more concrete directions are going to be followed in the future, in order to develop the same logic of servicity.

\section{References}

Allais, Maurice 1978, La théorie générale des surplus, Presses Universitaires de Grenoble.

HeilbronerR. L. 1994, The Wordly Philosophers: The Lives, Times and Ideas of the Great Economic Thinkers (in Romanian), Bucharest, Humanitas Printing House.

Jivan, Al. 1995, The Economics of the Intellectual tertiary sector (in Romanian), Timisoara, Mirton

Jivan, Al. 2000, Servicity - more than productivity in service economy (in Romanian), Sedona Publishing House, Timisoara, 2000

Jivan, Al 2006, "Responsabilizing and Servicity", Proceedings of the $3^{\text {rd }}$ International

Conference "Economy and Transformation Management", Université d'Avignon et des Pays de Vaucluse, France, University of the West, Timişoara, Faculty of Economic Sciences, Jean Monnet European Centre of Excellence, The School of High Comparative European Studies (SISEC), Timişoara, Romania, May 5- 6, 2006

Jivan, Al 2007, "From Georgescu-Roegen to Manoilescu. And further to Sen", in International Scientific Symposium "Economy, Society, Civilization”, Bucharest, 6-7 Juillet 2007, ASE Bucarest

Jivan, Al 2008, "Marketing, Liberalist Spirit and Nature", Timişoara Journal of Economics (TJE), Vol. I Issue (nr.) 4, p. 321-342

Jivan, Al.; Talpoş I.; Mirica, M.; Popovici, A. 2010, "Economic Roots of the Transformations in Intellectual Behaviours in Romania Nowadays. Focus on Education and Scientific research", in Globalization and Higher Education in Economics and Business Administration, IV th International Conference, Octobre 2123, 2010, Iasi, Romania, Vol. I, Publishing House of the "Alexandru Ioan Cuza" University, Iaşi, pp. 218-229).

Jivan, Al 2011a, "Completions to Marshallian Out-Look, Consistent with Knowledge Based Economy", Timisoara Journal of Economics (TJE), Vol. 4 Issue 1(13)

Jivan, Al 2011b "Artificial Economy", Journal of Knowledge Management, Economics and Information Technology, issue 5, august 2011, www.ScientificPapers.org, pp. 1-20

Jivan, Al 2013a "Needs Hierarchy and Genuine Productivity", in the volume, Applied Social Sciences: Economics and Politics, ISBN (10): 1-4438-4334-2, ISBN (13): 978-14438-4334-8, Cambridge Scholars Publishing, London, UK, 2013, pp. 57-64

Jivan Al 2013b, "Levels of Analyzing Productivity. Theoretical Settings", Annals. Economics Science Series, Volume XVIII, Tibiscus University, Eurostampa Publishing House, Timişoara, pp. 351-359 
Jivan Al 2013c, "Relative Value and Principles of Servicity", Journal of Knowledge Management, Economics and Information Technology, Volume III, Issue 4, August, www.ScientificPapers.org, pp. 154-183

Jivan, Al 2014, "Productivité et servicité, Economies et Sociétés, No. 4/2014, Cahiers de l'ISMEA, No 4/2014 (Série "Economie et Gestion des Services » EGS No 15, Avril), pp 579-599

Johnston R., Jones P. 2004, "Service productivity: Towards understanding the relationship between operational and customer productivity", in International Journal of Productivity and Performance Management,2004; 53, 3/4; ProQuest Central p. 201

Kemppila S, Lonnqvist A 2003, "Subjective productivity measurement", in Journal of American Academy of Business, Cambridge; Mar 2003; 2, 2; ProQuest Central p. 531

Maslow A.H. 1968, Toward a Psychology of Being, Van Nostrand Reinhold Company, New York

Manoilescu M. 2012, Opere complete, vol. I, Forțele naționale productive și comerțul exterior. Schema teoretică a comerțului internațional (Complete Works, volume I, The national productive forces and the extern commerce), Bucharest, Publishing House of Romanian Academy

Offer A. 2012, "Self-interest, Sympathy and the Invisible Hand: From Adam Smith to Market Liberalism", All Souls College, University of Oxford, avner.offer@allsouls.ox.ac.uk (20 July), accessed on the $19^{\text {th }}$ of March 2014

Quesnay F. 1766, Analyse de la formule arithmétique du tableau économique de la distribution des dépenses annuelles d'une nation agricole (juin), http://ebook.librairiedurance.fr/2500000586606-analyse-de-la-formule-arithmetiquefrancois-quesnay/

Ramirez W.Y., Nembhard A.D. 2004, "Measuring knowledge worker productivity - a taxonomy", in Journal of Intellectual Capital, 5, 4; ProQuest Central p. 602

Sedlacek T 2012, Economia binelui şi a răului. În căutarea sensului economic, de la Ghilgameş la Wall Street. Ed. PUBLICA

Sen A.K. 2000, On Ethics and Economics, Oxford: Blackwell

Smith A. 1759, The Theory of Moral Sentiments, The second edition, London, A. Millar, Eginburg, MDCCLIX http://www.econlib.org/library/Smith/smMS.html, accessed on the $18^{\text {th }}$ of March 2014

Smith A. 1993, An Inquiry into the Nature and Causes of the Wealth of Nations. Chicago, Robert P. Gwinn, Publisher, Encyclopaedia Britannica, Inc.

Stănciulescu A. 2005, Mic dicţionar enciclopedic al limbii române. Bucureşti: Editura Enciclopedică.

Veblen T. 1953, The Theory of the Leisure Class. An Economic Study of Institutions, The New American Library (with The Viking Press, Inc.)

Wilson A, Frimpong J. 2004, "A reconceptualisation of the satisfaction-service performance thesis", The Journal of Services Marketing; 18, 6/7; ProQuest Centralp. P.471

*** Webster's Reference Library, Concise Dictionary and Thesaurus, Geddes \& Grosset, 2002, Reprinted 2006 